\title{
Transportation Equity
}

\section{Rafael H. M. Pereira}

Institute for Applied Economic Research - Ipea, Brazil

\section{Alex Karner}

The University of Texas at Austin, USA

\section{Abstract}

Transportation equity is a way to frame distributive justice concerns in relation to how social, economic, and government institutions shape the distribution of transportation benefits and burdens in society. It focuses on the evaluative standards used to judge the differential impacts of policies and plans, asking who benefits from and is burdened by them and to what extent. Questions of transportation equity involve both sufficientarian and egalitarian concerns with both absolute levels of wellbeing, transport-related poverty and social exclusion as well as with relative levels of transport-related inequalities. Ultimately, the study of transport equity explores the multiple channels through which transport and land use policies can create conditions for more inclusive cities and transport systems that allow different people to flourish, to satisfy their basic needs and lead a meaningful life. Transportation equity issues broadly encompass how policy decisions shape societal levels of environmental externalities and what groups are more or less exposed to them, as well as how those decisions affect the lives of different groups in terms of their ability to access life-enhancing opportunities such as employment, healthcare and education. Equity is a crucial part of a broader concern with transport and mobility justice. The call for transport justice goes beyond distributive concerns, and yet justice cannot be achieved without equity. 


\section{Definitions}

Transport and urban policies have implications for multiple dimensions of social life; adequate transportation services and/or well-located housing can mean the difference between getting and keeping a job, accessing healthy food, getting to school on time, or reaching needed medical care. Decisions to build or not build specific types of transportation infrastructure in specific places can result in changes to community cohesion, exposure to air pollution, and road safety risks. The moral concern with transportation equity encompasses the multiple channels through which transport and land use policies can create conditions that allow different people to flourish, to satisfy their basic needs and lead a meaningful life.

In cities around the world, transport and mobility policies create equity issues on a daily basis. Consider the following examples:

- Bus rapid transit systems that reallocate road space from private vehicles to public transport in cities like Bogota, Dar es Salaam, and Beijing disadvantage drivers while benefiting public transit users.

- Parking and congestion pricing in London and Singapore disproportionately burden lowincome drivers. But mitigating policies, like reinvesting revenue in public transit, can potentially offset any apparent disadvantage.

- An \$80-million (USD) bridge built in Sao Paulo dedicated exclusively for private motor vehicles, where public transport, cyclists and pedestrians are prohibited exclusively benefits drivers while siphoning funds away from other modes.

- The precarious state of the pedestrian and cycling infrastructure in Nairobi, Cairo and countless other cities across the Global South routinely creates life-threatening situations for non-drivers.

- Automobile dependency in cities like Atlanta or Houston forces low-income people and others who would prefer not to drive into automobile ownership so that they can access affordable housing as well as health and education services.

- Low-income communities and communities of color are disproportionately exposed to externalities like traffic fatalities and pollution because of their residential settlement patterns, segregation, gentrification, and displacement. 
Each of these examples highlights a common aspect of transport decision making: planners and policy makers have to prioritize the allocation of scarce resources, meaning that plans and policies inevitably benefit some groups at the expense of others. Evaluating the nature and extent to which benefits and burdens differ across groups is the central core of distributive justice.

Transportation equity is a way to frame distributive justice concerns in relation to how social, economic, and government institutions shape the distribution of transportation benefits and burdens in society. It focuses on the evaluative standards used to judge the outcomes of policies and plans, asking who benefits from and is burdened by them and to what extent.

\subsection{Equity as part of a broader idea of justice}

Transportation equity is a crucial part of a broader concern with transport and mobility justice. Transport justice encompasses moral and political concerns related to equity, democracy and diversity in the pursuit of more just cities and mobility systems. The concern with equity (distributive justice) relates to how the institutions and rules that govern society shape social and economic inequalities among its members. It focuses on the evaluative standards used to judge the outcomes of policies, asking who benefits from and is burdened by them and to what extent. Meanwhile, the concern with democracy relates to the fairness of the political processes related to participation in decision making. It involves the challenge of moving beyond periodic voting and overcoming technocratic top-down planning practices, and it is based on the core ideal that everyone's opinion should be equally heard in the decision-making processes that form institutions, policies and community organizations that shape the built environment (Fainstein, 2010). Finally, the concern with diversity involves the constant struggles over which rights and entitlements should be recognized and enforced. It requires the recognition of group-based differences and identities and promoting diversity in decision-making processes, acknowledging that participatory democracy is constantly marked by structural inequalities of wealth and power that marginalize certain groups and favor others in their ability to influence policy decisions (Young, 1990). Related to the concerns with democracy and diversity is the idea of the "right to the city". This idea is undergirded by the structural uneven geographies of power and privilege in cities and the political struggles over who has the power to influence and shape urbanized space 
(Enright, 2019). It is broadly understood as a claim for people to reshape the processes of urbanization through collective action and self-management to complement or challenge existing government policies, or to fill a gap where there is a lack of governmental action.

\section{Why is transportation equity important?}

Questions of transportation equity provide a valuable moral compass that help assess the fairness of the distribution of the benefits and burdens of transport policies (van Wee, 2011). Equity, nonetheless, is not so much about the unequal allocation of resources (transport services, investments, infrastructure) across space per se. Rather it is about how policy decisions shape societal levels of environmental externalities and what groups are more or less exposed to them, just as how they affect the lives of different groups in terms of their ability to access life-enhancing opportunities such as employment, healthcare and education (Pereira et al., 2017).

A comprehensive understanding of transport and mobility justice requires a multidimensional effort to grasp the distributive implications of urban and transportation policies while critically examining the political processes and institutional context that determine those distributive outcomes. A research focus on transportation equity, nonetheless, is valuable in its own right. Policy choices often reflect societal biases and can widen and deepen social and spatial inequalities, and the study of social and spatial inequalities can help make visible the structural biases underlying the organization of societies and governments. Even when governments have general redistribution systems, for example through taxation policies and subsidies, implementing regressive transport policies that disproportionately benefit the well-off is not justified. Because transportation needs vary widely depending on one's personal constraints (including mode availability, residential location, and workplace), transportation equity requires spatially targeted policies and interventions, as opposed to those that are more general and society-wide. Furthermore, public policies have a crucial role to play in social democracies through the provision of public goods and services, including public transit and large infrastructure projects. In this sense, public transport services and investments remain one of the key drivers that can shape spatial inequalities of development and opportunities in cities, making the study of the distributional effects of transport policies particularly important. Finally, even a genuinely diverse, democratic 
and inclusive participatory planning process is not a sufficient condition to ensure that the outcomes of transport policies are distributed equitably. The call for transport justice goes beyond distributive concerns, and yet justice cannot be achieved without equity.

\section{Theorizing Transportation Equity}

Researchers reflecting on transportation equity are often faced with four interrelated questions about distributive justice that cannot be addressed in isolation from one another:

1. What - that is, which benefits and burdens - should be distributed?

2. On which moral principles should distributions be based?

3. What is the fairest distribution?

4. Distribution among whom? ${ }^{1}$

Different theories of justice in the political philosophy literature (including utilitarianism, Rawls's egalitarianism, capability approaches and critical theories of justice) can lead to different answers to these questions. These theories are receiving increasing attention in the academic transport and mobilities literature (Davoudi \& Brooks, 2014; Martens, 2016; Pereira et al., 2017). There are some general agreements in the literature about how these questions should be addressed in the context of transport policies.

\subsection{Distribution of what: benefits and burdens}

The transport literature usually focuses on four types of transport-related benefits and burdens that are related to people's well-being: transport resources, mobility as in observed travel behavior, accessibility levels and transport externalities (Lucas et al., 2019). Analyses of the distribution of transport resources and travel behavior can be problematic. The focus on the distribution of resources, such as car ownership or proximity to transport infrastructure, for example, can be

\footnotetext{
${ }^{1}$ Questions related to the decision-making process and who has a voice in it are important but related to diversity and democracy concerns in transportation justice; they are beyond the scope of this chapter on transportation equity.
} 
misleading because it does not account for people's needs and preferences, and it does not reflect people's capability to use such resources to move in space and reach desired destinations. In turn, analyses of differences in travel behavior, such as in trip frequency or commute times, often cannot untangle how much of those inequalities emerge from individuals' tastes and preferences (voluntary choice) or from contextual constraints outside individual control. While travel patterns are closely linked to individuals' levels of well-being and participation in society, travel behavior data alone do not provide information about whether long commute times reflect constrained housing options in poor and distant locations or whether they reflect preferences for suburban living or other 'expensive tastes'. Transport decisions are not always, if rarely, a matter of individual rational choice as it is often assumed in the literature.

Transportation equity studies have found more fertile ground when looking at accessibility and transport externalities. The primary benefit of transportation infrastructure and services is to improve people's accessibility, or the ease with which they can reach key destinations including employment, healthcare, and educational opportunities. Multiple authors have argued that the concept of accessibility should be at the center of understanding transportation benefits and equity for various reasons (Martens, 2012; Pereira et al., 2017). Some minimum level of accessibility to key destinations is necessary for people to satisfy their basic needs. It also has instrumental importance to support out-of-home activity participation and the freedom of choice that allows people to develop their capabilities and flourish. Moreover, understanding the causes of disparities in access to opportunities reveals the spatial dimension in moral concerns over inequality of opportunities, which is a central theme across theories of justice but which has been largely addressed as a non-spatial problem by political philosophers and social scientists.

Accessibility is also attractive as a planning goal because it brings together transportation and land use (Manaugh et al., 2015). Because people travel to meet opportunities that are widely dispersed in space, bringing origins and destinations closer together affects the demand for travel. These types of land use policies also support urban environments conducive to reducing automobile use and increasing walking and cycling. Such policies can also create situations where land prices and rents increase, displacing long-time residents to suburban and exurban areas. These types of secondary and tertiary effects of transportation and land use policies must be considered when attempting to meet equity goals. 
One challenge with accessibility as a concept is that there is no consensus on how it should be measured (Lucas et al., 2019; Neutens et al., 2010). Most commonly in the literature accessibility is calculated by summing up the number of activities (e.g. jobs or schools) reachable from an origin location using either a defined travel time threshold (e.g., 45 minutes of public transit travel time) or by weighting closer opportunities more heavily. These types of measures are attractive because they can be easily calculated using readily available data. Nevertheless, a broad sense of accessibility also involves issues such as affordability, security, safety, universal design and social practices. A more rigorous account of transportation equity should consider how accessibility levels are influenced by personal characteristics such as age, race, gender or physical and cognitive disabilities and how such characteristics relate to local contexts of social and built environments.

Ideas about transportation system benefits have certainly shifted throughout the latter half of the 20th century in academia, but these changes are slow to diffuse to practice. The situation is most challenging in the automobile-dominated economies of the United States, Canada, Australia and many nations in the Global South. Automobile-centric planning values travel time and specifically congestion mitigation over accessibility. The focus on reducing travel times and congestion often leads to inequitable and ineffective policies (Martens, 2016; van Wee, 2011). This is in part because the monetary valuation of travel time savings that are commonly conducted in conventional project appraisal methods (such as cost-benefit analysis) implicitly favors transport investments that primarily benefit higher-income groups. Moreover, attempts to tackle congestion and reduce travel times by adding roadway capacity ultimately leads to more congestion through a process known as "induced demand." With reduced travel times, people make more trips or shift trips from other routes to locations that have new capacity. In the medium term, this leads to land use changes. This realization suggests that congestion is not solvable in the aggregate, but providing alternatives to driving can improve the situation for individuals. An accessibility perspective makes this clear.

Transportation equity concerns also relate to the distribution of transportation burdens, who causes those burdens and who gets exposed to them (Feitelson, 2002; Schweitzer \& Valenzuela, 2004). Transportation burdens include various health-related concerns stemming from exposure to air pollution, sedentary lifestyles, and increased risk of injury and death from collisions. Most of 
these burdens have historically been inequitably distributed, with low-income people and people of color overrepresented in terms of their population shares of proximity to heavily trafficked roads, respiratory illnesses, and rates of injury and death. Disadvantaged populations also tend to reside in areas with lower-quality pedestrian and cycling infrastructure and where traffic conditions are more dangerous, subjecting them to increased risk of death or severe injury when collisions occur. On the other hand, studies have shown that high-income populations are disproportionately responsible for flights and private vehicle use, which are responsible for overwhelming shares of transport pollution (Mattioli, 2016). Efforts to mitigate these disparities have been uneven. In Global North countries, air quality has been steadily improving over time even as levels of driving continue to increase. In the Global South, on the other hand, rising automobility, the use of older vehicles for longer periods of time, and unfavorable geography, have all contributed to dramatically worse air quality in places like Beijing, New Dehli, and Santiago.

Efforts to mitigate these health concerns can sometimes have unintended consequences. For example, a popular approach to increasing traffic safety includes adopting "Vision Zero" policies that have as their goal reducing or eliminating traffic deaths. A popular method for achieving Vision Zero in cities around the world involves increasing police presence in locations where traffic incidents are concentrated. But these also tend to be locations disproportionately populated by disadvantaged populations. Cyclists in particular are vulnerable when police presence increases because they are often violating laws (either knowingly or unknowingly) as a matter of necessity or because of financial constraints. Riding on the sidewalk to avoid heavilytrafficked streets is one example. Riding without lights or a helmet is another. While lights are often required while riding at night, they are somewhat costly to maintain because they require batteries and are easy targets for theft. These minor legal violations give police an opportunity to stop, question, and potentially search cyclists. Depending on demographics, the presence of a cycling culture, and infrastructure, the types of people bicycling will differ substantially. Attitudes towards cycling will also tend to differ. In many locations in the US, for example, cycling is a deeply marginalized choice and this is reflected in the demographics of those who choose to ride. Increased policing and enforcement can produce a very dangerous situation for these cyclists. 


\subsection{Guiding moral principles}

Regardless of the specific benefits and burdens that are considered as part of an inquiry into transportation equity, applying different moral principles will result in different understandings about how such benefits and burdens should be distributed. Two broad types of moral concerns that are commonly applied in the transportation equity literature but rarely explicitly articulated come from sufficientarian and egalitarian perspectives.

A sufficientarian approach to justice considers whether the distribution of goods and bads in society allow everyone to meet a generally acceptable standard of living. Stated differently, absolute levels matter more than relative inequalities for sufficientarianism. Adherents would not be concerned with differences across groups, as long as all achieve above a certain threshold of, say, transport accessibility or air quality (Martens, 2016).

Sufficientarian concerns are reflected in various ideas that permeate the transportation literature and practice. Much attention has been given to issues related to environmental justice and public health, looking for example at whether certain ethnic minority neighborhoods and other vulnerable groups are exposed to exceedingly high levels of transport air pollution. A growing body of research also focuses on the ideas of "needs gaps" and "transit deserts." These studies seek to quantify a "gap" between the level of public transport service (supply) and the needs of a particular population (demand), and identify as "deserts" those locations where demand outpaces supply levels. Most of these research are not explicitly grounded in theoretical frameworks on justice or basic needs, even though they take an implicitly sufficientarian perspective without naming it as such. These studies depart from the idea that there exists a minimum level of transport resources, services, safety or accessibility that is necessary for people to fulfill basic needs and lead a meaningful life, or conversely that there is a maximum amount of transport externalities such as air pollution that is deemed acceptable. A corollary to this idea of a minimum standard is that public action is necessary to guarantee the needs of people who fall below that threshold.

In contrast to sufficientarians, egalitarians are fundamentally concerned with the relative distribution of goods and bads among members of society. From an egalitarian perspective, for example, even if all individuals in a city had above acceptable levels of access to job opportunities by public transport, for example, this situation would still be deemed unfair if a population group 
had relatively lower access as a result from a discriminatory policy against them. This is a strong reason why transport justice problems cannot be defined solely based on sufficientarian concerns. Egalitarianism encompasses the idea that all individuals have equal moral worth and should be treated as equals in some respect, even though different theories of justice might disagree about what kinds of equality (resources, life outcomes, wellbeing, opportunities etc.) are more morally relevant.

Transport inequalities are a common egalitarian concern found across the transport equity literature, even though the majority of this research is not explicitly grounded on any theory of justice. Typically, studies in this tradition investigate for example the extent to which certain groups or neighborhoods are disproportionately more exposed to transport externalities or why certain groups are better served by public transport and have higher transport accessibility levels than others (e.g. Bullard \& Johnson, 1997). The implication is that these inequalities could reflect deeper structural factors such as historic discriminatory policies and other disadvantages that undermine the transport experience of certain groups and further exacerbate injustices.

A fair transport policy is guided by both sufficientarian and egalitarian concerns. It aims to improve for example overall levels of transport safety or accessibility and reduce transport externalities so that everyone is above acceptable thresholds, while at the same time prioritize improving the conditions of disadvantaged groups and reduce inequalities. However, promoting minimum levels of transport goods/bads and reducing inequalities, is not sufficient to guarantee a just urban and transport policy. A necessary condition for a policy to be considered fair, is that it cannot not override the basic rights and liberties of individuals and minority groups even if it promotes a greater good to a greater number of people (Pereira et al., 2017). Particularly in Global South, is it still more often the norm than the exception that governmental officials use this type of utilitarian discourse to justify the eviction of poor communities in order to expand road and transport infrastructure.

In summary, a fundamental characteristic of an equitable transport policy or project is that its implementation respects people's basic rights and liberties, such as the physical and psychological liberty and integrity of the person. Furthermore, it should both prioritise improving the conditions of disadvantaged groups and reduce transport-related inequalities, and at the same time account for people's basic needs ensuring that all individuals achieve above a certain 
threshold of essential transport goods/bads, whatever those thresholds may be given a set of environmental constraints. On the whole, this sets a theoretical framework that is flexible enough to accommodate universalist concerns about the protection of basic rights, the satisfaction of basic needs and promotion of equality of opportunities without losing sight of context-specific issues regarding the particularities of each urban context and that the notions of basic needs and minimum thresholds are historically and culturally dependent.

\subsection{What is a fair distribution}

These moral concerns of egalitarianism and sufficientarianism suggest whether relative or absolute levels of goods and bads should be considered, but these principles alone do not determine whether a specific distributional outcome is judged to be equitable. Studies that follow a sufficientarian perspective often adopt a technocratic approach and assume implicitly the minimum levels that require policy intervention can be defined through a "technical" decision based on empirical data analyses alone, without any moral or political judgment. Nonetheless the definition of what an "adequate" level of transport accessibility or externality means is ultimately a political decision that deeply reflects the vision of a just city and mobility system each society aspires to build and which is highly dependent on local and historical context. For policy purposes, setting those thresholds ultimately requires a legitimate political and democratic process.

Studies that take an egalitarian stand, on the other hand, generally do not specify why the transport inequalities they analyze should be deemed unfair and implicitly assume the mere existence of any inequality is put forth as evidence of unfairness. One standard that could be used when defining whether a given transport inequality should be deemed inequitable is whether an observed disparity results from the unfair treatment of disadvantaged groups and whether such inequality could undermine/compromise their life chances. It is not the level of inequality per se that determines whether a given distribution is inequitable, although oftentimes this magnitude can be very telling of deeper injustices.

Moreover, studies that focus on transport inequalities, as a rule, do not clearly state how far policies should go to mitigate them. At the outset, it is important to note that a situation of perfect equality (whether of transport resources, services, accessibility etc.) is not possible because 
of how societies are (spatially) organized, even if some might consider full equality to be desirable. Nonetheless, there is a growing consensus in both transport planning practice and in the academic literature that a fair transportation policy should prioritize improving the conditions of people in the worst-off positions, helping to pull them above acceptable minimum thresholds and reducing inequalities (Pereira et al., 2017). Despite various differences of ideas between and within egalitarian and sufficientarian views of justice, it is commonly accepted that equality does not necessarily equate with equity and that in some cases the pursuit of justice requires that individuals or groups be treated differently to compensate for unfair conditions and inequalities. This is one of the reasons why it becomes increasingly important to move beyond cross-sectional descriptive analysis of transport poverty and transport inequalities, and look more closely at how and to what extent the implementation of various policy interventions can contribute to promote fairer and more inclusive cities and mobility systems.

\subsection{For whom}

Each of the prior considerations can be set without consideration of specific population groups for whom outcomes should be assessed and compared. The literature and practice has very clearly focused on population groups known to be disadvantaged because of low-income, ability, and historical discrimination (Lucas, 2019). For example, relevant groups include youth, older adults, women, low-income people, zero-vehicle households, people with disabilities, single-parent households, refugees, and racial/ethnic minorities. There is a common understanding that these are morally arbitrary characteristics, beyond individuals' control, but which often undermine people's transport experience because of historic discriminatory policies and other disadvantages. This emphasis in the literature also arises in part from the sense that these groups have been historically excluded from the transportation planning process as well as legal frameworks that require transportation planners to explicitly consider their needs (Grengs, 2002; Karner \& Niemeier, 2013).

Transportation disadvantages can manifest in various ways (Lucas \& Jones, 2012; Mullen et al., 2014). They occur when there are not enough transport resources/services available to an individual or household for them to participate in desired activities. They can also occur when 
there are enough resources/services but these are inadequate for people with disabilities. Transport disadvantages can also occur when vulnerable groups are disproportionately exposed to environmental externalities, or when the transport experience, physical and mental health of a person or group are undermined, limited or put at risk because they are from a ethnic minority or gender in a given social and built environment. While a few studies use the term 'modal equity' to refer to inequalities between transport modes, equity is about people. Disparities between transport modes (say of road space, or accessibility etc) only become equity issues because of the systematic differences in the socio-demographic characteristics of those who predominantly reap the benefits and bear the externalities of different modes.

Although there is no absolute standard for when a particular situation rises to the level of disadvantage, researchers have identified that social exclusion can result if transportation needs are not met. This situation can result in trips being foregone with attendant poor outcomes including difficulty finding and keeping a job, inability to reach medical care, difficulty accessing educational opportunities, and limited social connections. Historically disadvantaged groups in a transportation equity context are disadvantaged because of their risk of social exclusion (Lucas, 2019).

A transportation equity perspective that focuses attention on the needs of these groups is important because transportation planning has historically responded to the needs of the most mobile and has sought to further improve their mobility. This emphasis is most clear in the automobile-oriented transportation planning that has commonly occurred in Canada, Australia, and the United States and across countries in the Global South.

Legal frameworks in the United States that respond to that country's unique and problematic history of racism, unequal treatment, and discrimination against people of color require public agencies to ensure that their policies and practices are not discriminatory (Bullard, Johnson, \& Torres, 2004), although the methods agencies use to demonstrate nondiscrimination can often be inconsisent with best practices developed in the academic literautre (Karner \& Niemeier, 2013). The Americans with Disabilities Act (ADA) also requires agencies to provide equal accommodations for people with disabilities, but this often manifests in paratransit services that are viewed as a lower tier than fixed-route options. In the early 1990s, the United Kingdom made strides in efforts to combat social exclusion, forming an official government arm to 
implement policy across a number of issue domains, including transport. Difficulties with developing appropriate transport-specific metrics and tying them to real-world planning efforts meant that that effort did not result in material gains on social exclusion.

\section{The future of transportation equity}

The pace of technological change in transportation is creating profound disruption and dislocation across the industry that challenges existing frameworks related to transportation equity. Questions regarding the appropriate role for private organizations in providing mobility, the effects of connected and automated vehicles on public transit provision, the desirability of "micro" transit and on-demand transit services, and the role of bike share and other "micromobility" solutions on travel outcomes all warrant increasing attention.

In the coming decades, the transport industry will increasingly rely on algorithms to support the planning, management and allocation of automated vehicles and mobility services, for example with the use of artificial intelligence and big data predictive modeling to develop flexible routing and scheduling of services. There is a growing awareness of the ways in which big data and algorithms often reflect the biases underlying broader social and political processes. The lack of critical reflection and algorithmic transparency raises the risk of decision-making processes that inadvertently reflect those biases and end up reinforcing injustices. While much of the current research on automated vehicles and shared mobility systems focuses on how to make them commercially viable, more research is needed to understand how these changes in technology and governance will reshape who gets access, when, and how, and what implications they might have for questions of equity, public health and environmental justice.

In the meantime, the rise of transportation network companies (TNCs) ${ }^{2}$ is already leading directly to declines in public transit ridership in cities around the world. TNCs operate best when there is a high density of origins, destinations, and potential riders, so that wait times are

\footnotetext{
${ }^{2}$ Variously referred to as ridehailing, ridesourcing, and (incorrectly) ridesharing organizations, these are companies that provide users with the ability to summon a vehicle to serve a trip on demand.
} 
minimized. Locations where these conditions prevail are also those where public transit is most likely to succeed. The practical result has been diminishing public transit ridership and increasing congestion in cities where TNCs have been active the longest. Some observers have hailed this development as another example of successful "disruption" of an outdated public transit business model. What these observers fail to realize is that public transit provides essential lifeline mobility to those who need it most in locations that would otherwise be unprofitable to serve. Private mobility providers simply cannot be relied upon to serve the diversity of markets that public transit serves. Indeed, public transit operators intentionally provide service in locations that they know will not generate a profit so that residents have some access to transportation services. They also operate large vehicles to accommodate peak travel demand, minimize maintenance challenges, and streamline driver licensing and certification.

The influx of private mobility providers into markets previously served by public transit has led to a push for increasing "microtransit" or on-demand service. The problem with these calls is that microtransit does not scale well. Where public transit is most effective, operators save time by not deviating from a fixed route to reach every user at their origin and destination. Instead, they collect riders at common origins and destinations, with riders required to complete the first and last mile. A microtransit system that provides every customer with door-to-door service would create substantial unreliability and unpredictability at relatively modest levels of demand. It may provide a viable option in certain types of first/last-mile situations and in areas where public transit demand is relatively low.

A perennial issue with TNCs as a transportation equity measure involves the problem of un/underbanked populations and smartphone access. Access to credit is often a prerequisite for using the smartphone apps that enable TNC access and many lower income people simply do not have access. While smartphone penetration rates continue to increase across all population groups, limitations on data plans are more likely to affect low-income people and thus their ability to access private mobility providers. Spatial discrimination also continues to be a problem, with evidence of TNC drivers avoiding certain neighborhoods out of real or perceived fear.

One response to the challenges of public transit in general is to provide automobiles to those experiencing transportation disadvantages in an effort to mitigate their social exclusion by encouraging automobility. Multiple researchers have examined the effect of such a policy on 
outcomes and the results are promising. Providing low-income people with cars increases the likelihood of finding and keeping a job and can lead to long-term increases in earnings. The problem, unfortunately, is that this solution also does not scale and come at an environmental cost (Mattioli, 2016). Giving all low-income people cars will saddle already vulnerable households with additional debt and monthly costs that may or may not be offset by increased revenue, increase risks of injury and death, and accelerate the climate crisis. Additionally, the cities that have grown up around automobility run contrary to the basic principles of city building that have accumulated over decades, increasing car dependency and thus limiting mobility and accessibility choices for non-drivers.

Indeed, urban planners are concerned with understanding the types of places people want and how to create them. Encouraging more driving cannot be the solution to transportation equity issues (Mattioli, 2016). More promising alternatives that address equity without exacerbating the climate crisis and leading to unintended health consequences are possible but they involve looking beyond transport to consider land use, housing, and institutional barriers in an integrated manner. Despite the knowledge that travel demand is intimately related to land use, transport practitioners still rarely consider housing and land use solutions to transport problems. Creating places where people do not have to use the car to access and hold a job, where they can make healthy transport decisions, and where their share of household income allocated to transport and housing is held to a reasonable level is a more promising--and proven--strategy for achieving transportation equity that does not rely on the benevolence of private entities nor does it require us to rely on the gamechanging promise of new technology. To achieve transportation equity, we need to ensure that all residents of our cities and regions can safely reach the opportunities that they need to thrive. 
Preprint: Pereira, R. H. M. \& Karner, A. (forthcoming) Transportation Equity. In R. Vickerman (Ed.), International Encyclopedia of Transportation (2021). $1^{\text {st }}$ Edition, Elsevier.

\section{Further reading}

1. Bullard, R. D., \& Johnson, G. S. (Eds.). (1997). Just Transportation: Dismantling Race \& Class Barriers to Mobility. Gabriola Island, BC: New Society Publishers.

2. Bullard, R. D., Johnson, G. S., \& Torres, A. O. (Eds.). (2004). Highway Robbery: Transportation Racism \& New Routes to Equity. Cambridge, MA: South End Press.

3. Davoudi, S., \& Brooks, E. (2014). When does unequal become unfair? Judging claims of environmental injustice. Environment and Planning A, 46(11), 2686-2702.

4. Enright, T. (2019). Transit justice as spatial justice: learning from activists. Mobilities, 14(5), 665-680.

5. Fainstein, S. S. (2010). The just city. Ithaca: Cornell University Press.

6. Feitelson, E. (2002). Introducing environmental equity dimensions into the sustainable transport discourse: issues and pitfalls. Transportation Research Part D: Transport and Environment, 7(2), 99-118. doi:10.1016/S1361-9209(01)00013-X

7. Grengs, J. (2002). Community-Based Planning as a Source of Political Change: The Transit Equity Movement of Los Angeles' Bus Riders Union. Journal of the American Planning Association, 68(2), 165-178.

8. Karner, A., \& Niemeier, D. (2013). Civil rights guidance and equity analysis methods for regional transportation plans: a critical review of literature and practice. Journal of Transport Geography, 33, 126-134.

9. Lucas, K. (2019). A new evolution for transport-related social exclusion research? Journal of Transport Geography, 81, 102529. https://doi.org/10.1016/j.jtrangeo.2019.102529

10. Lucas, K., \& Jones, P. (2012). Social impacts and equity issues in transport: an introduction. Journal of Transport Geography, 21, 1-3. doi:10.1016/j.jtrangeo.2012.01.032

11. Lucas, K., Martens, K., Ciommo, F. D., \& Dupont-Kieffer, A. (Eds.). (2019). Measuring Transport Equity (1 edition.). Cambridge, MA: Elsevier.

12. Manaugh, K., Badami, M. G., \& El-Geneidy, A. M. (2015). Integrating social equity into urban transportation planning: A critical evaluation of equity objectives and measures in transportation plans in North America. Transport Policy, 37, 167-176. doi:10.1016/j.tranpol.2014.09.013 
13. Martens, K. (2012). Justice in Transport as Justice in Accessibility: Applying Walzer's 'Spheres of Justice' to the Transport Sector. Transportation, 39(6), 1035-1053.

14. Martens, K. (2016). Transport justice: Designing fair transportation systems. London: Routledge.

15. Mattioli, G. (2016). Transport needs in a climate-constrained world. A novel framework to reconcile social and environmental sustainability in transport. Energy Research \& Social Science, 18, 118-128. doi:10.1016/j.erss.2016.03.025

16. Mullen, C., Tight, M., Whiteing, A., \& Jopson, A. (2014). Knowing their place on the roads: What would equality mean for walking and cycling? Transportation research part A: policy and practice, 61, 238-248.

17. Neutens, T., Schwanen, T., Witlox, F., \& Maeyer, P. D. (2010). Equity of urban service delivery: a comparison of different accessibility measures. Environment and Planning A, 42(7), 1613 - 1635. doi:10.1068/a4230

18. Pereira, R. H. M., Schwanen, T., \& Banister, D. (2017). Distributive justice and equity in transportation. Transport Reviews, 37(2), 170-191. doi:10.1080/01441647.2016.1257660

19. Schweitzer, L., \& Valenzuela, A. (2004). Environmental Injustice and Transportation: The Claims and the Evidence. Journal of Planning Literature, 18(4), 383-398. doi:10.1177/0885412204262958

20. van Wee, B. (2011). Transport and Ethics: Ethics and the Evaluation of Transport Policies and Projects. Cheltenham: Edward Elgar Pub.

\section{Key words}

1. Transportation equity

2. Transport justice

3. Distributive justice

4. Environmental justice

5. Externalities

6. Sufficientarianism

7. Egalitarianism
8. Transport inequality

9. Transport poverty

10. Transport disadvantage

11. Social exclusion

12. Social justice

13. Mobility justice 